\title{
PENGARUH PENGGUNAAN SKIMMERTERHADAP ABNORMALITAS PADA PEMELIHARAAN LARVA IKAN KERAPU BEBEK, Cromileptes altivelis
}

\author{
Suko Ismi*), Eri Setiadi**), Wardoyo", dan Tridjoko*)
}

\begin{abstract}
ABSTRAK
Dengan keberhasilan produksi benih kerapu bebek, masih banyak kendalakendala yang harus diperbaiki di antaranya kualitas benih, yaitu morfologi benih kerapu bebek dari hasil produksi perbenihan masih ada yang cacat seperti insang terbuka, mulut bengkok, tulang belakang bengkok, dan sebagainya yang akan mengganggu pertumbuhan bila dibudidayakan, selain mempunyai harga yang murah dan rentan terhadap penyakit. Diduga salah satu penyebab cacat adalah tidak berkembangnya gelembung renang pada larva yang diakibatkan ketidakmampuan larva mengambil udara di permukaan air yang tertutup oleh lapisan minyak. Karena itu untuk membersihkan lapisan minyak di permukaan air perlu adanya penelitian penggunaan skimmer dengan waktu yang berbeda yaitu: saat larva berumur 6 hari; 15 hari, dan tanpa skimmer. Hasil yang diperoleh adalah penggunaan skimmer pada larva berumur 6 hari menghasilkan sintasan dan pertumbuhan lebih baik di samping mempunyai persentase perkembangan gelembung renang yang lebih tinggi dan persentase benih yang cacat lebih rendah dibanding dengan perlakuan yang lain.
\end{abstract}

ABSTRACT: Effect surface skimmer on deformity of humpback grouper (Cromileptes altivelis) Iarval rearing. By: Suko Ismi, Eri Setiadi, Wardoyo, and Tridjoko

Grouper seed production is still facing some problems to be improved on then quality, one of the problems from hatchery is deformity. Some deformities occurred in humpback grouper i.e.: opened operculum, head bent upward, backbone bent etc., impairing growth and had cheaper price and high incidence of infected disease. One of deformity was caused by uninflated swimbladders resulted in disability to take air on water surface of covered by oil coat. To clean oil coat on the water surface using skimmer in different larval old is: larvae age 6 day; 15 day and without skimmer. Result obtained by using skimmer of 6 old day larvae resulted in better growth and survival rate with higher swimbladder level growth and lower deformity percentage seed compared to those other treatments.

KEYWORDS: skimmer, deformity, humpback grouper, larvae, oil coat

\section{PENDAHULUAN}

Salah satu kendala dari budi daya kerapu adalah pasok benih yang biasanya berasal dari tangkapan alam sehingga dari segi jumlah, kualitas, dan waktu yang tidak tepat dengan kebutuhan sehingga menjadi faktor penghambat dari perkembangan budi daya (Sugama et al., 2001). Saat ini hal tersebut sudah bisa diatasi karena benih kerapu telah dapat dipasok dari hasil pembenihan dalam jumlah yang cukup dengan ukuran yang seragam (Kawahara \& Ismi, 2003). Pasok benih kerapu dari hatcheri dapat dilakukan sepanjang tahun tanpa tergantung musim sehingga kebutuhan benih yang selama ini menjadi kendala bagi budi daya keramba jaring apung dapat ditanggulangi.

Peneliti pada Balai Besar Riset Perikanan Budidaya Laut, Gondol

**) Peneliti pada Balai Riset Perikanan Budidaya Air Tawar, Bogor 
Dengan keberhasilan dalam produksi benih, masih banyak kendala-kendala yang harus diperbaiki di antaranya kualitas benih, yaitu morfologi benih kerapu bebek dari hasil pembenihan banyak yang cacat, seperti insang terbuka, mulut bengkok, tulang belakang bengkok, dan sebagainya yang akan mengganggu pertumbuhan bila dibudidayakan (Boglione et al., 2001) selain mempunyai harga yang murah dan rentan terhadap penyakit (Sutarmat et al., 2002; 2003). Diduga beberapa faktor yang menyebabkan terjadinya cacat antara lain adalah genetik (Paperna, 1978; Piron, 1978) dan nutrisi (Kanazawa, 1985). Kekurangan vitamin C, D, dan phospholipids, trypthophan dapat menyebabkan pertumbuhan tulang tidak normal (Weis \& Weis, 1989; Akiyama et al., 1989) lingkungan seperti penanganan dan kepadatan telur, suhu, oksigen, intensitas cahaya, polutan pada air (Haya, 1989; Wiegand et al., 1989; Caris \& Rice, 1990), suhu dan salinitas (Lee $\&$ Menu, 1981), penyakit (Treasure, 1992) termasuk cara dan kondisi pemeliharaan (Barahona-Fernandes, 1982; Taniguchi et al., 1984; Divanach et al., 1997; Koumoundouros et al., 2001). Beberapa peneliti mengatakan bahwa tidak berkembangnya gelembung renang adalah termasuk salah satu sebab terjadinya cacat pada ikan (Kitajima et al., 1981; Daoulas et al., 1991).

Diduga salah satu penyebab cacat/ abnormalitas adalah tidak berkembangnya gelembung renang pada larva yang diakibatkan tidak mampunya larva mengambil udara di permukaan air yang tertutup oleh lapisan minyak. Untuk membersihkan lapisan minyak di permukaan air perlu adanya pemasangan
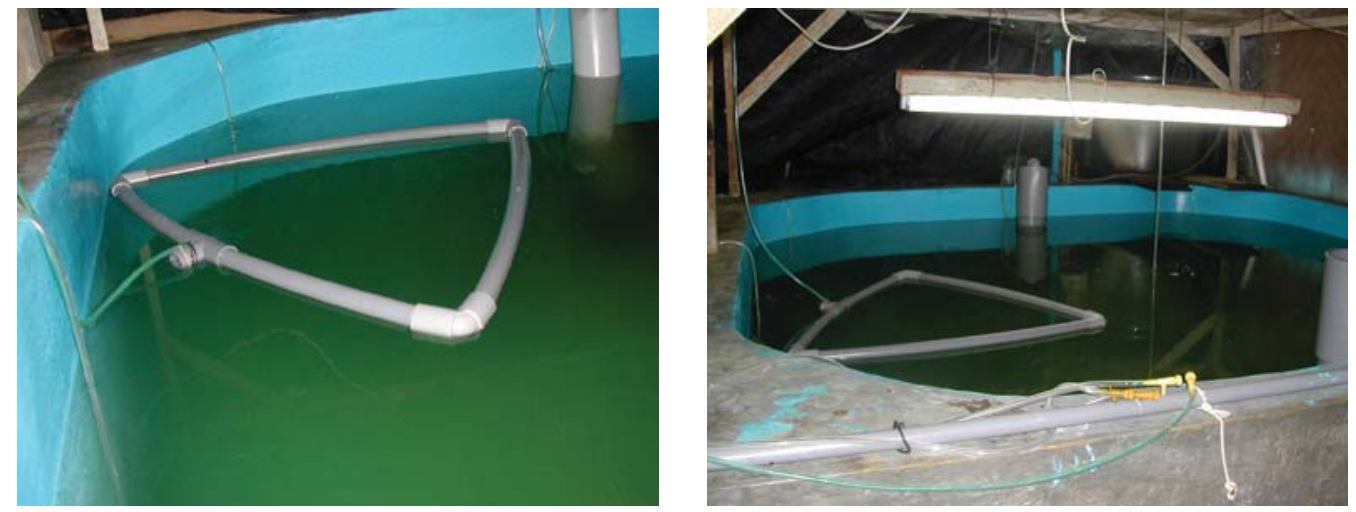

Gambar 1. Tangki pemeliharaan larva kerapu bebek dengan menggunakan skimmer

Figure 1. Larval rearing tank of humpback grouper with skimmer 
10 hari, seterusnya pergantian air bertambah hingga $50 \%$ pada umur 30 hari. Air mengalir dengan pergantian hingga $100 \%-150 \%$ jika larva telah mencapai umur 45 hari.

Untuk menentukan persentase normal dan abnormal dilakukan analisis pewarnaan tulang berdasarkan metode Potthoff (1984). Pengambilan sampel dilakukan secara berkala dari setelah menetas umur 1 hari (D1), (D5), (D10), (D15), (D20), (D25), (D30), (D40), (D55), (D70), dan (D90) dengan satu kali pengambilan sebanyak 20 ekor. Untuk mengetahui persentase perkembangan gelembung renang pada akhir penelitian yuwana di tes dengan pembiusan dan direndam pada salinitas $55 \mathrm{ppt}$, yuwana yang mengapung adalah yang mempunyai gelembung renang. Abnormalitas yang disebabkan cacat tulang dicoba dilihat dengan difoto melalui $X$ ray. Parameter yang lain adalah sintasan, pertumbuhan, dan kualitas air meliputi suhu, DO, salinitas, dan pH. Analisis data secara deskriptif.

\section{HASIL DAN BAHASAN}

Dari pengamatan secara akumulasi dari sampel yang diambil selama 90 hari pemeliharaan larva kerapu bebek diperoleh persentase abnormalitas berdasarkan hasil fisual dan pewarnaan tulang dapat dilihat pada Gambar 2.

Persentase abnormalitas secara fisual lebih rendah bila dibandingkan dengan pengamatan setelah pewarnaan hal ini disebabkan secara fisual nampak normal meskipun ikan tersebut cacat, dapat dilihat pada Gambar 5, di mana biasanya abnormal akan semakin tampak setelah ikan tersebut besar. Dari hasil nampak bahwa penggunaan skimmer pada saat larva berumur 6 hari abnormalitas ikan lebih rendah bila dibandingkan dengan penggunaan skimmer 15 hari dan tanpa penggunaan skimmer. Bagian-bagian tulang yang banyak mengalami abnormalitas adalah: centrum dan hypural, pada penggunaan skimmer 6 hari dan 15 hari, sedangkan tanpa penggunaan skimmer abnormalitas juga terjadi pada centrum, duri haemal, duri neural, anal proximal, dorsal proximal, prypural, hypural, dan epural. Besarnya persentase abnormalitas nampak pada Gambar 3.

Hasil pengamatan persentase adanya gelembung renang seperti terlihat pada Gambar 4.

Dari data yang diperoleh nampak bahwa pada penggunaan skimmer yang dipasang saat larva berumur 6 hari mempunyai persentase gelembung renang lebih banyak bila dibandingkan dengan penggunaan skimmer pada saat larva berumur 15 hari dan tanpa penggunaan skimmer. Hal ini diduga bahwa dengan penggunaan skimmer saat larva berumur 6 hari, larva ikan banyak mempunyai kesempatan mengambil udara bebas ke permukaan untuk membantu pembentukan gelembung renang. Seperti dikatakan oleh Blaxer (1986) dan Kitajima et al. (1994) bahwa ada dua cara untuk pembentukan gelembung renang yaitu dengan mengambil udara bebas

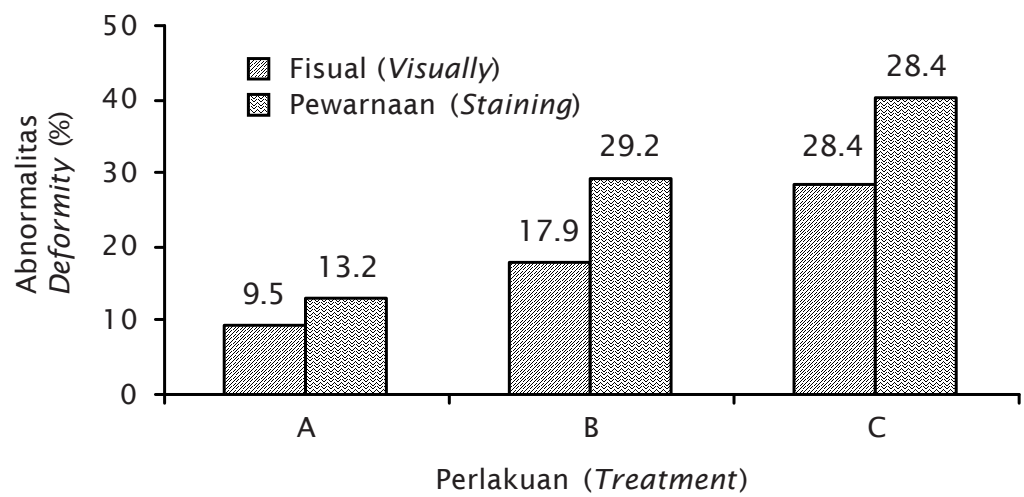

Gambar 2. Persentase abnormalitas berdasarkan pengamatan fisual dan pewarnaan tulang pada pemeliharaan larva dengan menggunakan skimmer A (6 hari), B (1 5 hari), dan C tanpa skimmer)

Figure 2. Deformity percentage observed visually and bone staining in larval rearing by using skimmer $A$ ( 6 day), $B$ ( 15 day), and $C$ (without skimmer) 


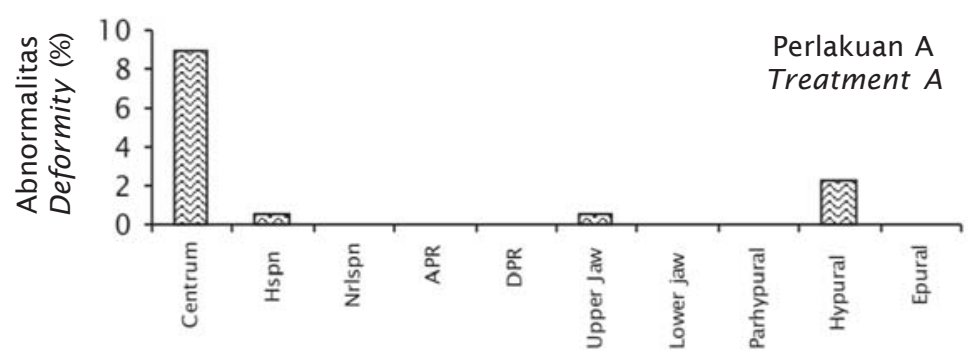

Bagian tulang (bone part)

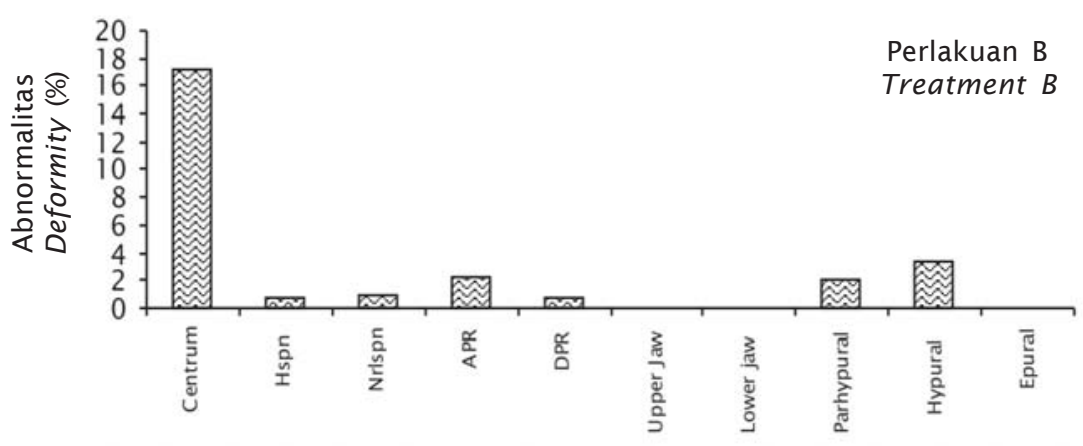

Bagian tulang (bone part)

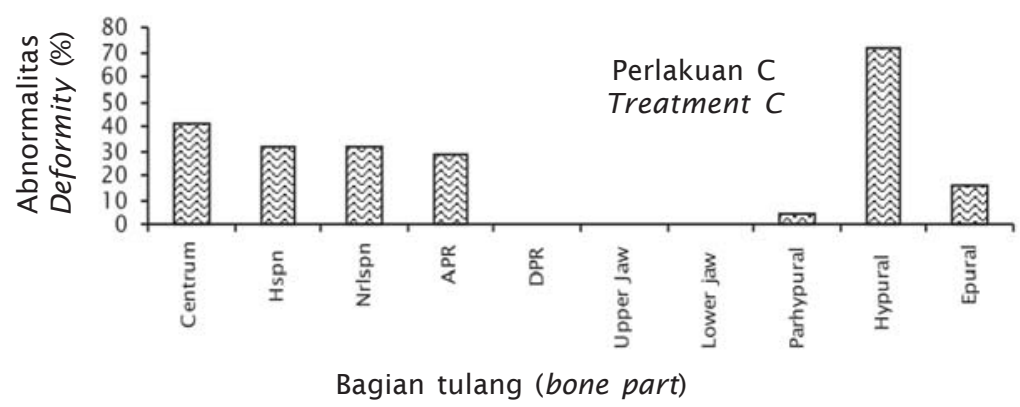

Gambar 3. Persentase abnormalitas berdasarkan bagian tulang pada penggunaan skimmer (A) saat larva umur 6 hari, (B) saat larva umur 15 hari, dan (C) tanpa skimmer

Figure 3. Percentage of deformity of bone part using up of skimmer $(A)$ in 6 old day larvae, (B) 15 old day larvae, and (C) without skimmer

dari permukaan air dan mengambil udara di dalam air secara difusi melalui aliran darah. Nampaknya pada penelitian ini gelembung renang banyak berkembang pada pemasangan skimmer lebih awal, tetapi sebelum larva berumur 6 hari pemasangan skimmer tidak dianjurkan karena pada saat larva berumur 15 hari untuk menghindari banyaknya larva yang mati akibat terjerat lapisan permukaan maka setiap hari ditambahkan minyak ikan untuk menutup lapisan permukaan (Sugama et al., 2001; Ismi et al., 2004). Pada penelitian ini nampak bahwa kebanyakan ikan yang cacat di antaranya disebabkan tidak berkembangnya gelembung renang, dapat dilihat dari hasil foto $X$ ray pada Gambar 6 . Nampak bahwa pada ikan yang cacat gelembung renangnya tidak berkembang.

Dari hasil pengamatan dengan pewarnaan dan foto $X$ ray nampak pada ikan yang normal secara pengamatan fisual ternyata tulang belakang mengalami cacat yaitu kiposis 


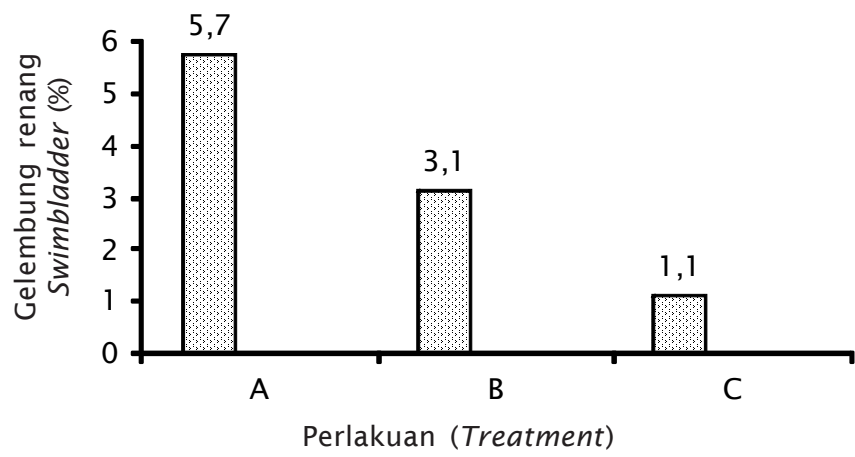

Gambar 4. Persentase adanya gelembung renang pada pemeliharaan larva dengan menggunakan skimmer A (6 hari), B (15 hari), dan C (tanpa skimmer)

Figure 4. Percentage of swimbladder in larval rearing by using skimmer $A$ (6 day), B (1 5 day), and C (without skimmer)
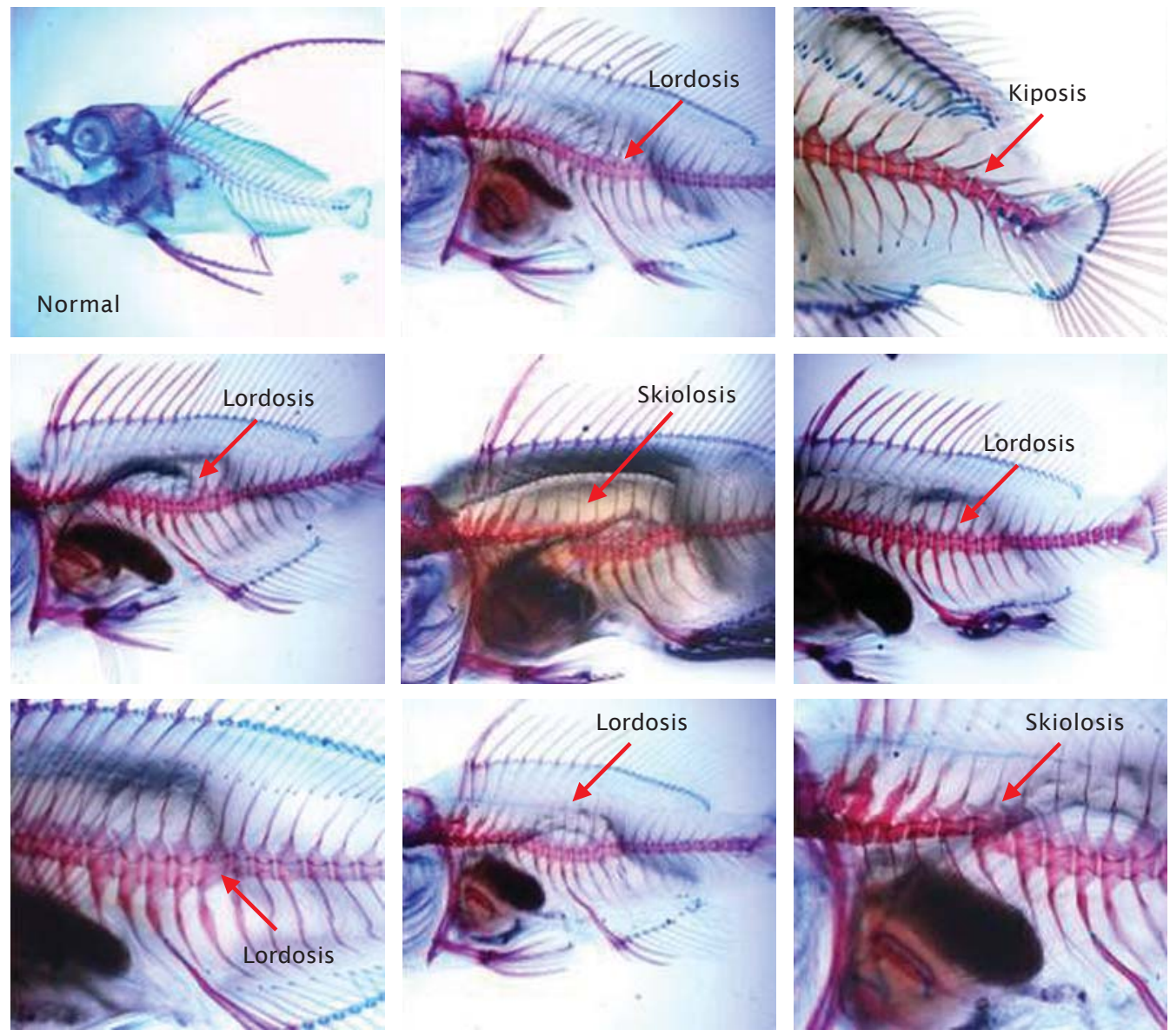

Gambar 5. Pengamatan dengan pewarnaan beberapa macam cacat tulang belakang

Figure 5. Observation by bone staining of some backbone bents 


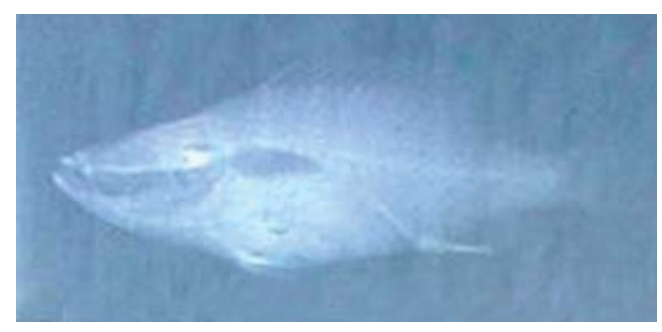

Normal dengan gelembung renang Normal with swim bladder

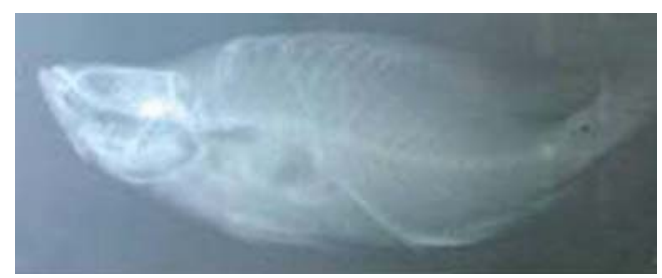

Kepala cacat

Head bent

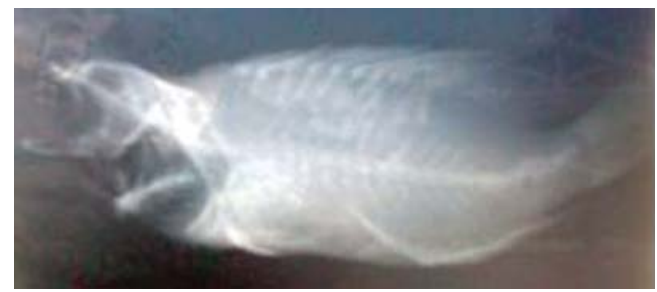

Kepala cacat, tulang belakang lordosis Head bent, backbone bents lordosis

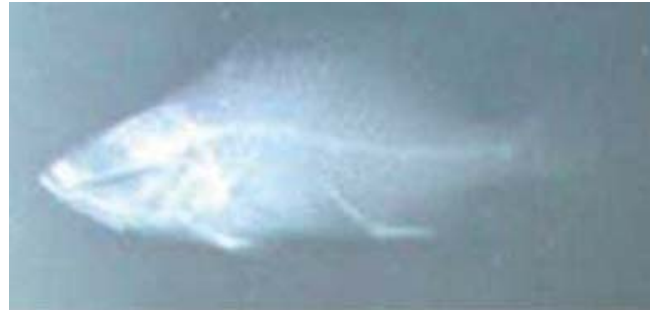

Normal tanpa gelembung renang Normal without swim bladder

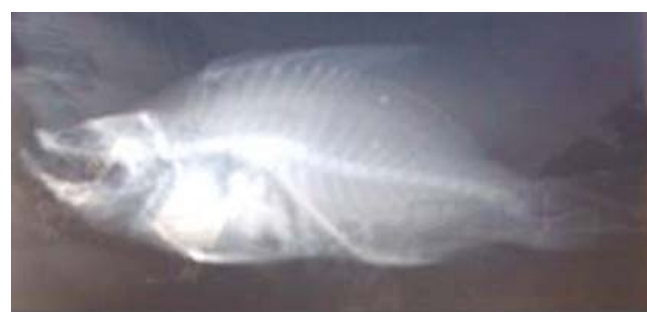

Bentuk tubuh tidak normal Deformity

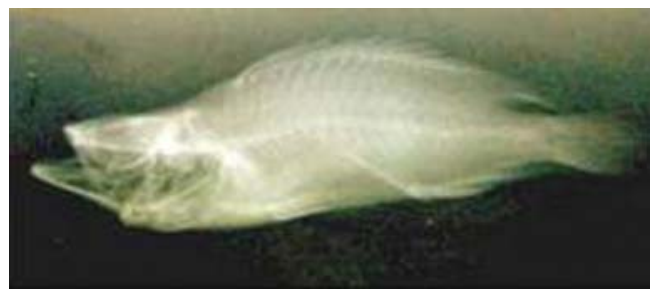

Kiposis

Gambar 6. Pengamatan dengan $X$ ray

Figure 6. Observasion by $X$ ray

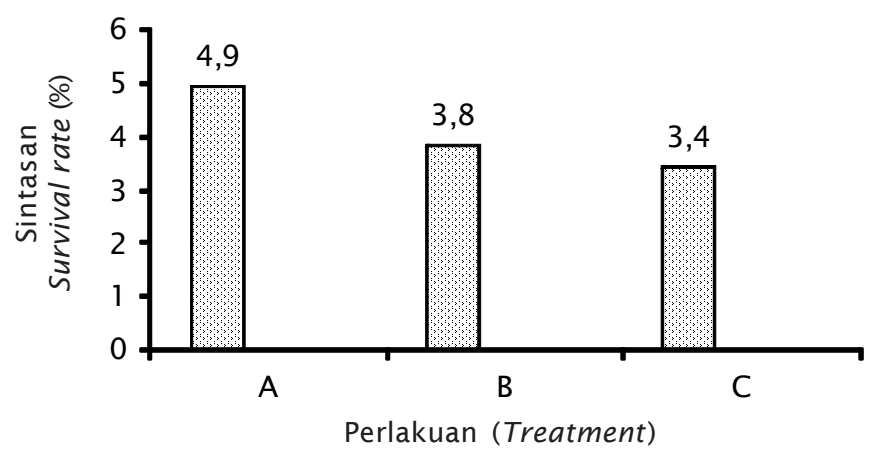

Gambar 7. Persentase sintasan hingga larva berumur 90 hari dengan menggunakan skimmer A (6 hari), B (15 hari), dan C tanpa skimmer

Figure 7. Percentage of survival rate on 90 old day larvae by using skimmer $A$ ( 6 day), $B$ (15 day), and C (without skimmer) 


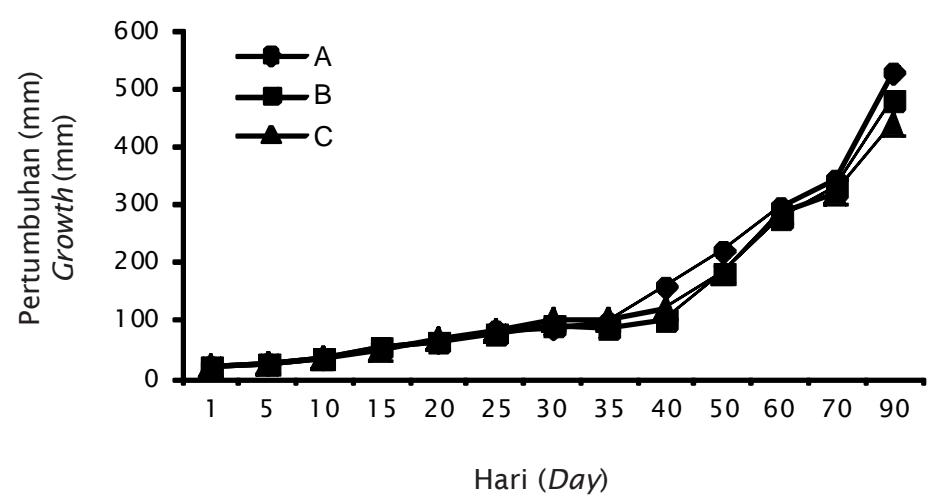

Gambar 8: Pertumbuhan larva kerapu bebek hingga berumur 90 hari dengan menggunakan skimmer A (6 hari), B (1 5 hari), dan C (tanpa skimmer)

Figure 8. Growth of humpback grouper larvae on 90 old day by using skimmer A (6 day), B (1 5 day), and C (without skimmer)

(bengkok ke atas) dan lordosis (bengkok ke bawah) dan bahkan ada tulang belakang yang mengalami skiolosis (seperti huruf S/bengkok ke atas dan ke bawah).

Sintasan dan pertumbuhan kerapu bebek selama penelitian dapat dilihat pada Gambar 7 dan 8. Dari hasil pengamatan diperoleh bahwa pada penggunaan skimmer saat larva berumur 6 hari mempunyai sintasan dan pertumbuhan lebih tinggi bila dibandingkan dengan penggunaan skimmer saat larva berumur 15 hari dan tanpa penggunaan skimmer.

Kualitas air selama pemeliharaan masih dalam taraf layak untuk pemeliharaan yaitu: suhu $\left(26^{\circ} \mathrm{C}-29^{\circ} \mathrm{C}\right), \mathrm{pH}(8,1-8,4 \mathrm{mg} / \mathrm{L}), \mathrm{DO}$ $(4,1-4,4 \mathrm{mg} / \mathrm{L})$, dan salinitas (33-34 ppt).

\section{KESIMPULAN}

- Penggunaan skimmer pada pemeliharaan larva kerapu bebek dapat mengurangi abnormalitas pada benih yang dihasilkan

- Penggunaan skimmer untuk pemeliharaan larva sebaiknya dipasang saat larva berumur 6 hari

\section{DAFTAR PUSTAKA}

Akiyama, T., T. Murai, and K. Mori. 1989. Role of triphophan metabolites in inhibition of spinal deformity of Chum Salmon fry caused by tryptophan deficiency. Bull. Jpn. Soc. Sci. Fish. 52: 1,249-1,254.

Barahona-Fernandes, M.H. 1982. Body deformationin hatchery reared European sea bass Dicentrarchus labrax (L). Types, prevalence and effect on fish survival. $J$. Fish Biol. 21 : 239-249.

Blaxter, J.H.S. 1986. Development of sense organs and behavior of teleost larvae with special reference to feeding and predator avoidance. Trans Am. Fish. Soc. 115: 98114.

Boglione, C., F. Gagliardi, F. Scardi, and S. Cataudella. 2001. Skeletal descriptors and quality assessment in larvae and post-larva of wild-caught and hatchery-reared gilthead sea bream (Sparus aurata L.). Aquaculture. 192: 1-22.

Caris, M.G. and S.D. Rice. 1990. Abnormal development and growth reductions of Pollock Theragra chalcogramma embryos exposed to water-soluble fractions of oil. Fish. Bull. US. 88: 29-37.

Daoulas, Ch., A.N. Economou, and I. Bantavas. 1991. Osteological abnormalities in laboratory reared sea bass (Dicentrarchus labrax) fingerlings. Aquaculture. 97: 169180.

Divanach, P., N. Papandroukalis, P. Anastasiadis, G. Koumoundouros, and M. Kentouri. 1997. Effect of water currents on the development of skeletal deformities in sea bass (Dicentrarchus labrax L.) with fuctional swimbladder during postlarval and nursey phase. Aquaculture. 156: 145-155.

Haya, K., 1989. Toxicity of pyrethroid insecticides to fish. Environ. Oxicol. Chem. 8: 381391.

Ismi, S., Wardoyo, K.M. Setyawati, Trijoko. 2004. Pengaruh frekuensi pemberian minyak ikan 
pada pemeliharaan larva kerapu bebek (Cromileptes altivelis). J. Pen. Per. Indonesia. 10(5): 61-65.

Kanazawa, A. 1985. Essential fatty acid and lipid requirement of fish. Nutrition and Feeding in Fish. Academic Press, London. p. 281-298.

Kawahara, S. dan S. Ismi. 2003. Statistik Produksi Benih Ikan Kerapu Indonesia 1999-2002. Balai Besar Riset Perikanan Budidaya Laut Gondol bekerjasama dengan Balai Budidaya Laut Lampung dan Balai Budidaya Air Payau Situbondo. Departemen Kelautan dan Perikanan.16 pp.

Kitajima, C., Tsukashima, Y., Fujita, S., Watanabe, T. and Yone, Y. 1981. Relationship between uninflated swimbladders and lordotic deformity in hatchery reared sea brem Pagrus major. Bull. Jpn. Soc. Sci. Fish. 47: 1,289-1,294.

Kitajima C., T. Waranabe, Y. Tsukashima, and S. Fujita. 1994. Lordotic deformation and abnormal development of swim bladders in some hatchery-bred marine physoclistous fish in Japan. J. World Aqua. Soc. 1: 65-77

Koumoundouros, G., P. Divanach, and M. Kentouri. 2001. The effect of rearing conditions on development of saddleback syndrome and caudal fin deformities in Dentex dentex (L). Aquaculture. 200: 285-304.

Lee, C. S. and Menu, B., 1981. Effect of salinity on egg development and hatching in grey mullet Mugil cephalus L. J. Fish Biol. 19: 179188.

Paperna., I., 1978. Swimbladder and skeletal deformations in hathery dred Sparus aurata. J. Fish Biol. 12: 109-114.

Piron, R.D. 1978. Spontaneous sketal deformities in Zebra Danio (Brachydanio rerio) for fish toxicity tests. J. Fish Biol. 13: 79-83

Potthoff, T. 1983. Clearing and straining techniques. In Ontogeny and Systematics of Fishes (Ed. By: H.G. Moser et al.) special
Publication I. American Society of Ichtyologist and Herpetologist. p. 35-37.

Sugama, K., Tridjoko, B. Slamet, S. Ismi, E. Setiadi dan S. Kawahara. 2001. Petunjuk Teknis Produksi Benih Ikan Kerapu Bebek, Cromileptes altivelis. Balai Riset Budidaya Laut Gondol, Pusat Riset dan Pengembangan Eksploirasi laut dan Perikanan Departemen Kelautan dan Perikanan dan Japan International Cooperation Agency. 40 pp.

Sutarmat. T, A. Hanafi, dan Kawahara. 2002. Leaflet Budidaya Kerapu bebek (Chromileptes altivelis) Di keramba jaring apung. Balai Besar Riset Perikanan Budidaya Laut Gondol bekerja sama dengan Japan International Cooperation Agency. 2 pp.

Sutarmat. T, S. Ismi, A. Hanafi, dan S. Kawahara. 2003. Petunjuk Teknis Budidaya Kerapu Bebek (Cromileptes altivelis) di Karamba Jaring Apung. Balai Besar Riset Perikanan Budidaya Laut Gondol, Pusat Riset Perikanan Budidaya Badan Riset Kelautan dan Perikanan. Departemen Kelautan dan Perikanan dan Japan International Cooperation Agency. 56 pp.

Taniguchi, N., K. Azumi., and S. Umeda. 1984. Difference due to parents in incidence of vertebral malformation in artificially-bred sea bream. Bull. Jpn. Soc. Sci. Fish. 50 (5): 787-792.

Tresure, J., 1992. Vertebral anomalies associated with Myxobolus sp. in perch, Perca fluvialitis L., in a Scoottish loch. Bull. Eur. Assoc. Fish Pathol. 12 (2): 63.

Weis, J.S. and Weis, P. 1989. Effects of environmental pollutans on early fish development. Aqua. Sci. 1: 45-73.

Wiegand, M.D., J.M. Hataley, C.L. Kitchen, and L.G. Buchanan. 1989. Induction of developmental abnormalities in larval goldfish, Carassius auratus L., under cool incubation conditions. J. Fish Biol. 35: 85-95. 